\title{
Saint-Sauveur-en-Puisaye (Yonne). La tour Sarrasine
}

Première étape de fouilles

\section{Virginie Jolly}

\section{(2) OpenEdition}

\section{Journals}

Édition électronique

URL : https://journals.openedition.org/cem/666

DOI : 10.4000/cem.666

ISSN : 1954-3093

Éditeur

Centre d'études médiévales Saint-Germain d'Auxerre

Édition imprimée

Date de publication : 15 août 2005

ISSN : 1623-5770

\section{Référence électronique}

Virginie Jolly, "Saint-Sauveur-en-Puisaye (Yonne). La tour Sarrasine », Bulletin du centre d'études

médiévales d'Auxerre | BUCEMA [En ligne], 9 | 2005, mis en ligne le 09 avril 2009, consulté le 22

septembre 2022. URL : http://journals.openedition.org/cem/666 ; DOI : https://doi.org/10.4000/cem. 666

Ce document a été généré automatiquement le 22 septembre 2022.

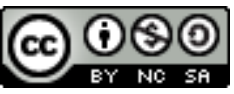

Creative Commons - Attribution - Pas d'Utilisation Commerciale - Partage dans les Mêmes Conditions 4.0 International - CC BY-NC-SA 4.0

https://creativecommons.org/licenses/by-nc-sa/4.0/ 


\section{Saint-Sauveur-en-Puisaye (Yonne). La tour Sarrasine}

Première étape de fouilles

Virginie Jolly

1 Le site de la tour "Sarrasine" de Saint-Sauveur-en-Puisaye a fait l'objet d'une campagne de relevés d'élévation et de sondages, qui a duré 4 mois au cours du printemps et de l'été 2004. Les archives concernant ce site sont rares et peu documentées. Aussi, ne connaissons-nous ni le commanditaire, ni la date de la première construction de l'édifice. Certains historiens la datent entre le $\mathrm{XI}^{\mathrm{e}}$ et le $\mathrm{XIII}^{\mathrm{e}}$ siècle, sans qu'aucune étude n'ait été menée sur le site. Or, les travaux de l'équipe du Centre d'études médiévales ont permis de resserrer partiellement la chronologie, tout en soulevant de nouvelles questions. La maçonnerie (en grès ferrugineux, liée d'un mortier de chaux, montée en joints larges et avec quelques pierres de chant, le système de faux joints sur les linteaux des rayères) et le type de mise en œuvre (trous de boulins traversants et fondation en appareil cyclopéen), nous laissent supposer que l'édifice date $d u \mathrm{X}^{\mathrm{e}}-\mathrm{XI}^{\mathrm{e}}$ siècle. Les traces d'outils sur les blocs de calcaire, la présence d'un système de poutres ceinturant l'édifice dans la maçonnerie, le plomb qui scelle les gonds des portes et fenêtres et surtout le plan plus ou moins ovoïdale, conduisent à l'hypothèse d'une tour du XII siècle.

2 Le changement de mortier et de méthode de construction (moellons ébauchés, pierre de chant...) attestent du fait qu'il y a eu au moins deux étapes simultanées de construction: la partie basse et la partie haute de la tour. Il est légitime de se demander si celles-ci sont le résultat d'un changement d'équipe et/ou de commanditaire. Dans l'attente des résultats de l'analyse des bois prélevés dans la tour, nous ne pouvons pas plus préciser sa datation (fin $\mathrm{XI}^{\mathrm{e}}$-début $\mathrm{XII}^{\mathrm{e}}$... sous réserve !).

3 L'étude des mortiers nous a aidé à déterminer trois autres grandes phases de travaux (et de nombreuses plus ponctuelles) qui s'échelonnent dans le temps. La plus ancienne daterait de la fin du Moyen Âge (XVe siècle), la seconde de la Renaissance (XVII ${ }^{\mathrm{e}}$ siècle),alors que la plus récente, aurait été effectuée au XIX (il semble possible de la mettre en relation avec les inscriptions relevées dans la niche). Bien que la finalité de 
cette tour ait pu paraître évidente de prime abord comme étant un simple édifice militaire, l'étude nous a permis de constater que cette conclusion était erronée. Ainsi, les rayères, faites de belles pierres de taille et agencées de façon à donner l'illusion d'un édifice militaire et puissant, ont fait l'objet d'un traitement particulièrement sophistiqué mais sont peu utiles pour laisser pénétrer la lumière. Le plan de l'édifice original, l'absence d'angle et l'étroitesse du côté défensif, renforcent l'impression d'un ouvrage à vocation guerrière. Pourtant, sur la vallée, la largeur de la façade, la grande taille de la porte, ainsi que l'absence de traces laissées par les éléments de confort à l'intérieur de l'édifice ne permettent qu'une hypothèse réellement défendable : la tour était un édifice ostentatoire qui servait plus à imposer la puissance du commanditaire qu’à protéger les habitants de la région.

Saint-Sauveur-en-Puisaye, la Tour Sarrasine

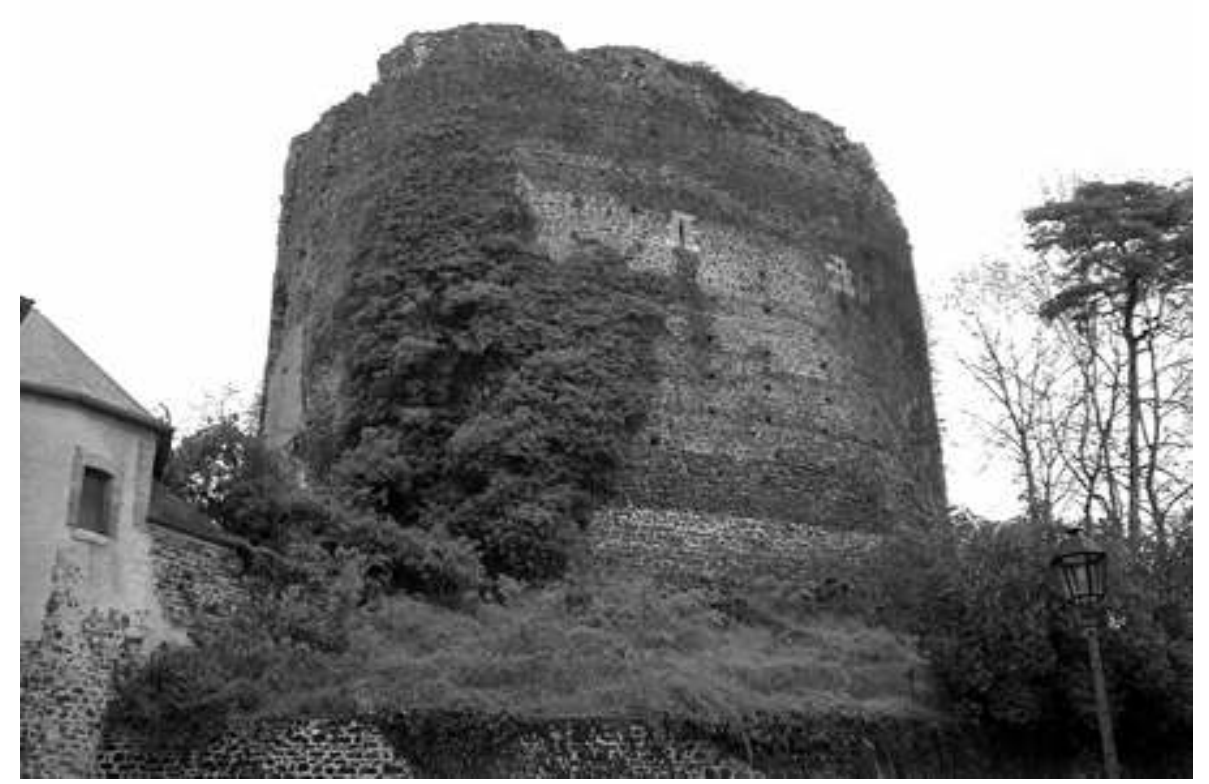

INDEX

Mots-clés : tour

Index géographique : France/Saint-Sauveur-en-Puisaye 